The mission of the Office of Motor Carrier and Highway Safety is to develop and promote, in coordination with other Departmental modes, data-driven, analysis-based, and innovative programs to achieve continuous safety improvements in the Nation's highway system, intermodal connections, and motor carrier operations. The Office of Data Analysis and Information Systems provides analytic and statistical support for all FHWA motor carrier and highway safety infrastructure program development and evaluation.

The Analysis Division analyzes motor carrier and highway safety crash trends, monitors patterns in motor carrier inspection rates, evaluates program effectiveness in reducing crashes, and researches crash causation and exposure data. It also conducts cost/benefit analyses and regulatory flexibility analyses to address new or revised regulations and policies, and coordinates information and data analysis with information and analysis specialists in the resource centers.

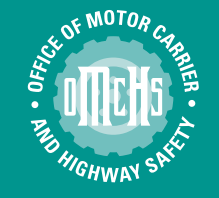

Office of Motor Carrier Research and Standards

400 Seventh Street, SW

HMCS-30; Room 3107

Washington, DC 20590

\section{Driver-Related Factors in Crashes Between Large Trucks and Passenger Vehicles}

\section{Introduction}

Large trucks (trucks with a gross vehicle weight rating of more than 10,000 pounds) are involved in close to 400,000 police-reported crashes each year, of which 4,500 involve a fatality. About 60 percent of fatal truck crashes involve one large truck colliding with a single passenger vehicle - a car, pickup truck, van, or sport utility vehicle. Prevention of these crashes requires understanding how and why these crashes occur to develop effective countermeasures.

The analysis of the relative contribution of the truck driver versus the driver of the other vehicle involved in a fatal crash has been limited in the past to an examination of the driverrelated factors variable in the National Highway Traffic Safety Administration's (NHTSA) Fatality Analysis Reporting System (FARS). The FARS analyst in each State records driver actions that may have contributed to the fatal crash. The coding is based on factors recorded on the crash report by the police officer. NHTSA's "Traffic Safety Facts 1996: Large Trucks" states that in 71 percent of two-vehicle fatal crashes involving a large truck and another vehicle, police reported "one or more errors or other factors related to the driver's behavior" for the other vehicle driver and none for the truck driver."

Analysts have been skeptical of relying solely on the judgments of officers at the scene of a crash to attribute cause or fault in fatal crashes. Thus, the Office of Motor Carrier and Highway Safety (OMCHS), in conjunction with the University of Michigan Transportation Research Institute (UMTRI), examined the driver-related factors from FARS along with other data that could either verify or rebut the factor data. This analysis brief presents the findings of this study.

\section{Methodology}

UMTRI maintains a fatal truck crash database called the Trucks Involved in Fatal Accidents (TIFA) file. In addition to including all the FARS data on fatal large truck crashes, the TIFA file contains additional information about these crashes collected from the truck drivers, the police officers, the truck companies and others with knowledge of the crash. The subject of this study were the 8,309 fatal crashes involving one large truck and one passenger vehicle in the 1994, 1995, and 1996 TIFA files. The analysis focused on two critical variables: driverrelated factors and accident type (captures the relative movement and position of the vehicles prior to the crash). Since certain movements and positions of the vehicles prior to the collision may indicate relative contribution to the occurrence of the crash, the reliability of the coding of the driver-related factors was evaluated.

\section{Discussion}

In fatal crashes involving one large truck and one passenger vehicle, errors on the part of the passenger vehicle driver were recorded significantly more often than errors on the part of the truck driver. In fatal crashes, up to three driver crash-related factors may be coded for each driver involved in a crash. Tables 1 and 2 compare the crash-related factors assigned to large truck and passenger vehicle drivers in fatal crashes involving both types of vehicles.

Reviewing the driver-related factors alone indicates that passenger vehicle drivers contributed disproportionately to fatal crashes involving a large truck and a passenger 
Table 1.

Large Truck Driver-Related Factors in Fatal Crashes* with a Single Passenger Vehicle

\begin{tabular}{|l|c|c|}
\hline $\begin{array}{l}\text { Large Truck Driver Factor } \\
\text { Coding }\end{array}$ & Number & Percent \\
\hline No Truck Driver Factor Coded & 6,051 & $73 \%$ \\
\hline $\begin{array}{l}\text { Factor(s) Coded for Truck Driver } \\
\text { Only }\end{array}$ & 1,325 & $16 \%$ \\
\hline $\begin{array}{l}\text { Factor(s) Coded for Truck Driver } \\
\text { and Passenger Vehicle }\end{array}$ & 830 & $10 \%$ \\
\hline Unknown & 103 & $1 \%$ \\
\hline Totals & $\mathbf{8 , 3 0 9}$ & $100 \%$ \\
\hline
\end{tabular}

*Involving one large truck and one passenger vehicle Source: TIFA 1994-1996

\begin{tabular}{|c|c|c|}
\hline \multicolumn{3}{|c|}{$\begin{array}{l}\text { Table } 2 . \\
\text { Passenger Vehicle Driver-Related Factors in } \\
\text { Fatal Crashes* with a Single Large Truck }\end{array}$} \\
\hline $\begin{array}{l}\text { No Passenger Vehicle Driver } \\
\text { Factor Coding }\end{array}$ & Number & Percent \\
\hline $\begin{array}{l}\text { No Passenger Vehicle Driver } \\
\text { Factor Coded }\end{array}$ & 1,477 & $18 \%$ \\
\hline $\begin{array}{l}\text { Factor(s) Coded for Passenger } \\
\text { Vehicle Driver Only }\end{array}$ & 5,875 & $71 \%$ \\
\hline $\begin{array}{l}\text { Factor(s) Coded for Passenger } \\
\text { Vehicle Driver and Truck Driver }\end{array}$ & 830 & $10 \%$ \\
\hline Unknown & 127 & $1 \%$ \\
\hline Totals & 8,309 & $100 \%$ \\
\hline
\end{tabular}

*Involving one large truck and one passenger vehicle Source: TIFA 1994-1996

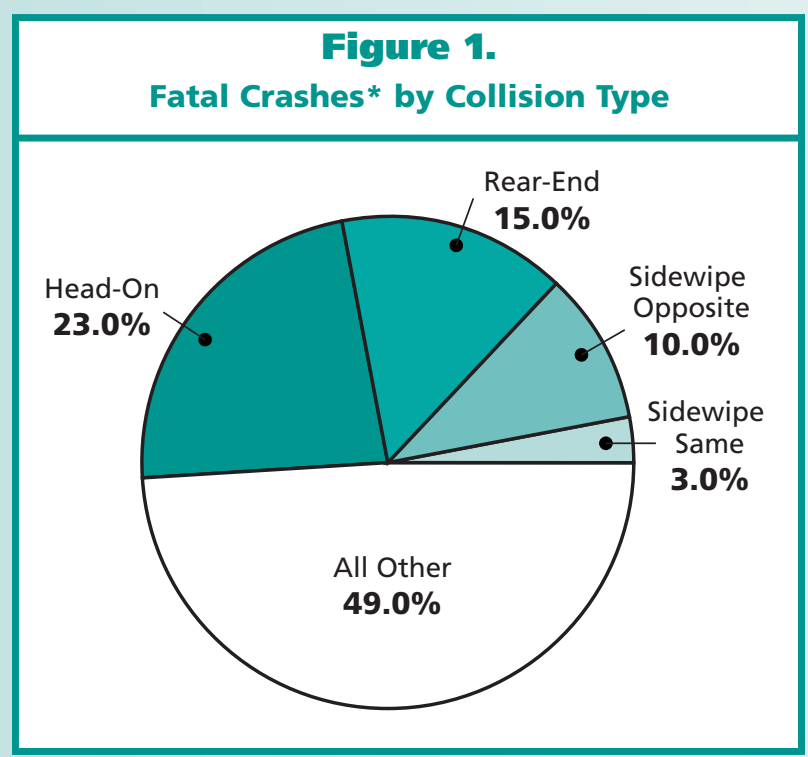

*Involving one large truck and one passenger vehicle Source: TIFA 1994-1996 vehicle. In the 8,309 fatal crashes, truck drivers were not coded with any driver-related crash factors in 73 percent of the crashes (Table 1). In contrast, only 18 percent of the passenger vehicle drivers were not coded with a driver-related factor (Table 2). In 16 percent of the crashes, the large truck was assigned crash factors, while in 71 percent of the crashes, the passenger vehicle was assigned crash factors. In 10 percent of the crashes both drivers were assigned crash factors.

One explanation offered for the disproportionate number of factors attributed to the passenger vehicle driver is that typically the passenger vehicle driver is killed in these crashes while the truck driver survives. The hypothesis is that the truck driver is available to give "his side" of the crash scenario and persuade the reporting police officer that the other driver was primarily at fault. In 83 percent of the crashes in the study, the truck driver survived and the passenger vehicle driver was killed, while in only 2 percent of the crashes the passenger vehicle driver survived and the truck driver was killed.

In 15 percent of the crashes in the study, both drivers survived and may have been able to describe the crash to the investigating officer. In 73 percent of these cases, the passenger vehicle driver was coded with a factor, while the truck driver was coded with a factor only 34 percent of the time. The distribution of driver-related factors for these cases remained close to the overall distribution for all fatal crashes.

Next, the driver-related factors were examined in light of the crash configuration to gain further insight in the validity of the coding of driver-related factors. The TIFA variable accident type captures the relative movement and position of the two vehicles prior to impact. Both the location of the vehicle in regard to its travel lane prior to impact and which was the striking vehicle can be determined from this variable. In some types of fatal crashes, this physical evidence of the crash configuration strongly suggests that one driver may have contributed more heavily than the other.

Four types of crash configurations were examined: head-on, rear-end, sideswipe (opposite and same direction), and all other configurations. Physical evidence for head-on and rear-end collisions probably indicates driver error. In a head-on crash where one vehicle crossed into the oncoming traffic lane, the evidence may indicate a greater contribution to the crash on the part of the driver that left his lane. In a rear-end collision, the striking vehicle may have contributed more heavily than the struck vehicle. The same is often true for sideswipes, whether the vehicles were going in the same or opposite directions. The driver that crosses into the other vehicle's lane probably contributed more heavily to the crash. However, in some sideswipes the physical evidence of where the collision took place is not as clear as for headons and rear-ends. For those cases, coding which vehicle encroached into the other vehicle's lane may depend on witness statements.

In other types of crashes - mostly angle collisions - the physical evidence does not give strong clues to implicate one vehicle or the other in the fatal crash. In one such 
type of crash, turning-across-path collisions, it is not clear which vehicle had the right of way. Similarly, in straight-path collisions, it is not clear which vehicle violated the right of way by running a stop sign or signal. determining fault in these types of crashes depends on statements from the drivers and witnesses, and may, therefore, may be less reliable.

Head-ons, rear-ends, and sideswipes (same and opposite direction) account for 51 percent of the fatal truckpassenger vehicle collisions (Figure 1). In these crash configurations, physical evidence exists that can indicate that one of the vehicles may have contributed more heavily to the crash occurring than the other. All other crash configurations account for 49 percent of the fatal crashes involving one large truck and one passenger vehicle. Each of the crash configuration categories is discussed below.

\section{Findings}

Head-On Crashes: In 89 percent of these fatal crashes, the passenger vehicle crossed the center line into the truck's lane, while in 11 percent of the crashes the truck encroached into the passenger vehicle's lane. Thus, the passenger vehicle encroached into the truck's lane of travel over eight times as often as the truck encroached into the passenger vehicle's travel lane.

The driver-related factor coding was consistent with the physical evidence in these head-on crashes. In the 212 crashes where the truck encroached into the lane of travel of the passenger vehicle, 93 percent of the truck drivers but only 10 percent of the passenger vehicle drivers were assessed with driver-related factors (Table 3).

Similarly, in the 1,724 crashes where the passenger vehicle encroached into the truck's lane of travel, 98 percent of the passenger vehicle drivers and only 9 percent of the truck drivers were attributed with crash factors. The percentages do not add to 100 percent, since in some of the cases both drivers were assessed with driver-related factors.

When large trucks encroached into the lane of the passenger car, 122 of the 212 truck drivers (58 percent) were coded as "failure to keep in the proper lane or running off the road." When the passenger vehicle encroached into the lane of the large truck, 1,199 of the 1,724 passenger vehicle drivers (70 percent) were assessed with "failure to keep in proper lane or running off the road."
Table 3.

Head-On Fatal Crashes* by Driver-Related Factors and Vehicle Maneuver.

\begin{tabular}{|l|c|c|c}
\multirow{2}{*}{$\begin{array}{l}\text { Encroaching } \\
\text { Vehicle }\end{array}$} & \multicolumn{2}{|c|}{ Driver-Related Factor Coded } & \multirow{2}{*}{$\begin{array}{c}\text { Total } \\
\text { Crashes }\end{array}$} \\
\cline { 2 - 3 } & Large Truck & Passenger Vehicle & 212 \\
\hline Large Truck & $93 \%$ & $10 \%$ & 1,724 \\
\hline Passenger Vehicle & $9 \%$ & $98 \%$ & \\
\hline
\end{tabular}

*Involving one large truck and one passenger vehicle

Source: TIFA 1994-1996

\section{Table 4.}

Rear End Fatal Crashes* by Driver-Related Factors and Vehicle Maneuver.

\begin{tabular}{|l|c|c|c|}
\hline \multirow{2}{*}{ Striking Vehicle } & \multicolumn{2}{|c|}{ Driver-Related Factor Coded } & \multirow{2}{*}{$\begin{array}{c}\text { Total } \\
\text { Crashes }\end{array}$} \\
\cline { 2 - 3 } & Large Truck & Passenger Vehicle & 252 \\
\hline Large Truck & $73 \%$ & $46 \%$ & 991 \\
\hline Passenger Vehicle & $19 \%$ & $94 \%$ & \\
\hline
\end{tabular}

*Involving one large truck and one passenger vehicle

Source: TIFA 1994-1996

Table 5.

Sideswipe Fatal Crashes* by Driver-Related Factors and Vehicle Maneuver.

\begin{tabular}{|l|c|c|c|}
\hline \multirow{2}{*}{ Striking Vehicle } & \multicolumn{2}{c|}{ Driver-Related Factor Coded } & \multirow{2}{*}{$\begin{array}{c}\text { Total } \\
\text { Crashes }\end{array}$} \\
\cline { 2 - 3 } & Large Truck & Passenger Vehicle & 100 \\
\hline Sideswipe: Opposite Direction & 766 \\
\hline Large Truck & $79 \%$ & $28 \%$ & \\
\hline Passenger Vehicle & $8 \%$ & $98 \%$ & 60 \\
\hline Large Truck & Sideswipe: Same Direction & 157 \\
\hline Passenger Vehicle & $83 \%$ & $37 \%$ & $97 \%$ \\
\hline
\end{tabular}

*Involving one large truck and one passenger vehicle

Source: TIFA 1994-1996

Rear-End Crashes: In rear-end fatal crashes in the study, the passenger vehicle was the striking vehicle almost four times as often as the large truck. The physical evidence was consistent with the coding of the driverrelated factor coding. The striking vehicle driver was assessed driver factors more often than the struck vehicle. In crashes where the passenger vehicle struck the truck, 94 percent of the passenger vehicle drivers and 19 percent of the truck drivers were assessed with driver-related factors (Table 4). In rear-end crashes where the large truck was the striking vehicle, 73 percent of the truck drivers and 46 percent of the passenger vehicle drivers were assessed driver-related factors.

Sideswipes: Opposite and same direction sideswipes account for 13 percent of the crashes in this study. In 
Researcher

This study was performed jointly by the Center for National Truck Statistics, University of Michigan Transportation Research Institute, and the Office of Data Analysis and Information Systems, OMCHS, Federal Highway Administration. Contract No: DTFH61-96-C0038.

\section{Distribution}

This Analysis Brief is being distributed according to a standard distribution. Direct distribution is being made to the Resource Centers and Divisions.

\section{Availability}

This Analysis Brief is available through the OMCHS Office of Data Analysis and Information Systems, Telephone: (202) 366-1861.

\section{Key Words}

large trucks, passenger vehicles, driver-related crash factors, head-on crashes, rear- end crashes, sideswipes.

\section{Notice}

This Analysis Brief is disseminated under the sponsorship of the Department of Transportation in the interest of information exchange. The Analysis Brief does not establish policies or regulations, nor does it imply FHWA endorsement of the conclusions or recommendations. The U.S. Government assumes no liability for its contents or their use.

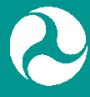

U.S.Department of Transportation Federal Highway Administration
Table 6.

All Other Fatal Crash* Configurations by Driver-Related Factors.

\begin{tabular}{l|c|c|}
\hline \multirow{2}{*}{ Driver Related Factor } & \multicolumn{2}{c}{ Number of Times Cited for Drivers } \\
\cline { 2 - 3 } & Truck & Passenger Vehicle \\
\hline Failure to Yield Right of Way & 417 & 1,622 \\
\hline Failure to Obey Traffic Devices & 274 & 950 \\
\hline Inattentive & 92 & 387 \\
\hline Driving Too Fast & 160 & 358 \\
\hline Ran Off Road/Lane & 108 & 246 \\
\hline Erratic/Reckless Driving & 80 & 150 \\
\hline
\end{tabular}

*Involving one large truck and one passenger vehicle Source: TIFA 1994-1996

opposite direction sideswipes, which have a similar crash configuration to head-on crashes, the passenger vehicle encroached into the truck's lane over seven times as often as the truck encroached into the passenger vehicle's lane (Table 5). In same direction sideswipes, the passenger vehicle encroached into the truck's lane about two and one half times as often as the truck encroached into the passenger vehicle's lane.

The driver-related factors coding was consistent with this physical evidence. When the passenger vehicle encroached into the lane in which the truck was traveling, the encroaching passenger vehicle driver was assigned driver factors in 98 percent of the opposite direction sideswipe crashes and 97 percent of the same direction sideswipe crashes. When the large truck was the encroaching vehicle, the truck driver was coded with driver-related factors in 79 percent of the opposite direction sideswipe crashes and 83 percent of the same direction sideswipe crashes. The most common driver-related factor coded for the encroaching vehicles, whether they were a passenger vehicle or a large truck, was running off the road or out of the traffic lane, both for opposite and same direction sideswipe crashes.

Other Crash Configurations: In all other crash configurations not discussed above, the physical evidence does not provide conclusive clues on driver contribution to fatal crashes. In the remaining 4,047 fatal crashes in this study, twice as many passenger vehicle drivers as truck drivers (77 percent versus 33 percent) are coded with driver-related factors (Table 6). The major factors cited for the drivers are similar to those recorded for the crash configurations already discussed above.

\section{Conclusion}

In about one-half of the fatal crashes between one large truck and one passenger vehicle, physical evidence about each vehicle's maneuver and position prior to the crash was available to help verify the coding of the driver-related factors. In these cases, the driver-related factors coding appeared to be consistent with the physical evidence. The drivers of vehicles that encroached into the other vehicle's lane in head-on and sideswipe crashes and drivers of vehicles that struck the other vehicle in rear-end crashes were assessed driver-related factors or errors more often than the other driver. In the majority of these cases, the passenger vehicle driver was attributed with driver-related factors or errors more often than the driver of the large truck.

While many of the OMCHS programs focus on motor carrier and truck driver safety, this analysis supports the importance of focusing on behavior of the drivers of the other vehicles. OMCHS already has programs in place, such as No Zone and car-truck proximity research, that are addressing these issues. However, more comprehensive data on the causes of large truck/passenger vehicle crashes of all severities would enhance OMCHS's ability to develop effective countermeasures and prevent future crashes. 